\title{
Influence of Cr203 Nanoparticles on the Structural, Optical, Thermal and Electrical Properties of PEO/CMC Nanocomposites
}

Laila Gaabour ( $\sim$ Lhgaabour@uj.ed.sa )

Jeddah University: University of Jeddah https://orcid.org/0000-0002-4020-3131

\section{Research Article}

Keywords: chromium (III) oxide (Cr203) nanoparticles, XRD, ATR-IR, TGA, AC conductivity.

Posted Date: May 24th, 2021

DOI: https://doi.org/10.21203/rs.3.rs-445027/v1

License: (c) (i) This work is licensed under a Creative Commons Attribution 4.0 International License.

Read Full License

Version of Record: A version of this preprint was published at Optical and Quantum Electronics on February 16th, 2022. See the published version at https://doi.org/10.1007/s11082-022-03565-3. 


\title{
Influence of $\mathrm{Cr}_{2} \mathrm{O}_{3}$ nanoparticles on the structural, optical, thermal and electrical properties of PEO/CMC nanocomposites
}

\author{
L. H. Gaabour \\ University of Jeddah, College of Science, Department of Physics, Jeddah, \\ Saudi Arabia
}

\begin{abstract}
In the present paper, different concentrations of chromium oxide $\left(\mathrm{Cr}_{2} \mathrm{O}_{3}\right)$ nanoparticles were incorporated within $\mathrm{PEO} / \mathrm{CMC}$ polymer blend to produce nanocomposite films using the casting method. The X-ray diffraction was performed on PEO/CMC-Cr ${ }_{2} \mathrm{O}_{3}$ nanocomposites. The main X-ray peaks of $\mathrm{Cr}_{2} \mathrm{O}_{3}$ were observed and defined as cubic structure and orthorhombic shape with an average particle size of the $\mathrm{Cr}_{2} \mathrm{O}_{3} \sim 50-80 \mathrm{~nm}$. The decrease of some IR bands after the addition of $\mathrm{Cr}_{2} \mathrm{O}_{3}$ nanoparticles was found attributed to the interactions between PEO/CMC and $\mathrm{Cr}_{2} \mathrm{O}_{3}$. Effect of $\mathrm{Cr}_{2} \mathrm{O}_{3}$ nanoparticles on optical properties such as absorbance and optical energy gap $\left(E_{\mathrm{g}}\right)$ were characterized using UV-Vis spectroscopy. The $E_{\mathrm{g}}$ was reduced after the addition of $\mathrm{Cr}_{2} \mathrm{O}_{3}$ nanoparticles. The $\mathrm{AC}$ conductivity $\left(\sigma_{\mathrm{ac}}\right)$, dielectric constant $\left(\varepsilon^{\prime}\right)$, dielectric loss $\left(\varepsilon^{\prime \prime}\right)$ and the dielectric modulus $\left(\mathrm{M}^{\prime}\right.$ and $\left.\mathrm{M}^{\prime \prime}\right)$ were calculated at frequency range $0.1 \mathrm{~Hz}-7 \mathrm{GHz}$. The increases of direct conductivity $\left(\sigma_{\mathrm{dc}}\right)$ imply that the free charge density or of the charge mobility that results. The estimated values of both $\varepsilon^{\prime}$ and $\varepsilon^{\prime \prime}$ were decreased with increases of frequency. The addition of $\mathrm{Cr}_{2} \mathrm{O}_{3}$ nanoparticles causes the formation of a charge-transfer complex. The Cole-Cole plot between $\left(\mathrm{M}^{\prime}\right.$ and $\left.\mathrm{M}^{\prime \prime}\right)$ shows a semi-circular shape confirm discuses according to a non-Debye method.
\end{abstract}

Keywords: chromium (III) oxide $\left(\mathrm{Cr}_{2} \mathrm{O}_{3}\right)$ nanoparticles; XRD; ATR-IR; TGA; AC conductivity.

Correspondence author: L. H. Gaabour, E-mail: lhgaabour@uj.edu.sa 


\section{Introduction}

The blending between different polymers is an attractive method as well as providing new materials at low cost during preparation. Polymer blends are used extensively in the literature due to their practical importance and use in various applications based on their properties[1,2]. The physical properties of the polymeric blend depend mainly on the morphology, and preparation methods. The importance of studying the properties of the blends is due to obtain new applications in several fields. Blending is an easy way to obtain new materials with improved and wider application properties [2-7]. In recent research, nanoscience has opened a new field for the uses of polymeric blending combined with some nanoparticles to be present on new nanocomposites.

Poly (Ethylene Oxide (PEO) is a widely studied polymer attributed to its multiple applications, but also as a model material for understanding the basic behaviour of polyethylene with polar units in the backbone series, PEO has the range ability to form a complex with nanomaterials. PEO has moderate strength, good mechanical and electrical properties. Some optical and electrical works are reported for using the electrolyte polymer film. The chemical composition of PEO because the presence of ether end groups, and -OH makes some possibilities for the formation Of the hydrogen bond which is confirmed by PEO with the other polymers during the blend method[8].

Carboxymethylcellulose (CMC) polymer is a cellulose derivative, and It is used in a wide range such as a thickener, bonding linkages, and stabilizers., etc. CMC has been widely applied in the medicinal products to its high-water absorption, morphogenetic, biodegradation, and biocompatibility uses. Also, CMC could have been mostly used as additive to other polymers due to their limited processability[3,9-11]. 
Nanoparticle materials are attracted increasing attention during the last years because of their physical properties with wide applications in different fields of technology. Several researchers have studied the dispersion of the nanoparticles in a polymer and/or polymer blend. The unique properties of the polymeric materials will enhance with the addition of some nanoparticles such as related to the composition, amount of the nanoparticles, particle size and the homogeneity between them [12,13]. Chromium oxide $\left(\mathrm{Cr}_{2} \mathrm{O}_{3}\right)$ molecules are important in different applications such as green dyes, corrosion resistance and thermal protection. $\mathrm{Cr}_{2} \mathrm{O}_{3}$ nanoparticles are attracted increasing attention in the last years because their individual properties. Several researchers focused on the dispersion of the $\mathrm{Cr}_{2} \mathrm{O}_{3}$ nanoparticles into a polymer matrix $[14,15]$.

From previous research, the physical properties of the metal nanoparticles, the nanoparticle materials filled inside them, are of interest due to their use in wide applications. Despite the existence of several previous studies studying nanoparticle materials with the PEO/CMC polymer blend, there are no complete studies to analyze the effect of $\mathrm{Cr} 2 \mathrm{O} 3$ on the physical properties $\mathrm{PEO} / \mathrm{CMC}$ blend. If our interest is in this work, we prepared new nanocomposites polymer material based on $\mathrm{PEO} / \mathrm{CMC}$ blend incorporated with low weight ratios $(0.0,0.2,0.4$ and 0.6 wt.\%) for $\mathrm{Cr}_{2} \mathrm{O}_{3}$ nanoparticles and studied the change of the structural, optical, AC electrical conductivity and dielectric properties, while comparing the obtained results with some of the previous reports.

\section{Experimental details}

\subsection{Materials}

Polyethylene oxide (PEO) powder with average molecular weight $\sim 1000000 \mathrm{~g} / \mathrm{mol}$ and carboxymethyl cellulose (CMC) with average 
molecular weight $\sim 90000 \mathrm{~g} / \mathrm{mol}$, and powder of chromium (III) oxide $\left(\mathrm{Cr}_{2} \mathrm{O}_{3}\right)$ nanoparticles with particles size $<100 \mathrm{~nm}$ with molecular weight $=151.99 \mathrm{~g} / \mathrm{mol}$ were obtained by Sigma Aldrich Company, UK.

\subsection{Synthesis of $\mathrm{PEO} / \mathrm{CMC}-\mathrm{Cr}_{2} \mathrm{O}_{3}$ nanocomposites}

Double distilled water was used as the common solvent of all the components. The solution casting technique was utilized to prepare the PEO/CMC blend and PEO/CMC doped with different contents of $\mathrm{Cr}_{2} \mathrm{O}_{3}$ nanoparticles. Firstly, equal weights $(2.5 \mathrm{~g})$ of both PEO CMC polymers were dissolved in $200 \mathrm{ml}$ of DD at $60{ }^{\circ} \mathrm{C}$ about $4 \mathrm{~h}$. Different concentrations $(0,0.2,0.4$ and 0.6 wt. $\%)$ of $\mathrm{Cr}_{2} \mathrm{O}_{3}$ nanoparticles were dispersed in $\mathrm{DD}$ water and added to $\mathrm{PEO} / \mathrm{CMC}$ according to the formula:

$$
\text { wt. } \%=\frac{w_{\mathrm{cr}}}{\mathrm{w}_{\mathrm{blend}}+\mathrm{w}_{\mathrm{Cr}}} \times 100
$$

where, $\mathrm{w}_{\text {cr }}$ is the weight of $\mathrm{Cr}_{2} \mathrm{O}_{3}$ and $\mathrm{W}_{\text {blend }}$ is the weight of PEO/CMC blend. The solutions of $\mathrm{Cr}_{2} \mathrm{O}_{3}$ nanoparticles were an addition to $\mathrm{PEO} / \mathrm{CMC}$ solution with stirring to prevent any agglomeration of the filler inside the blend. The final solutions of the PEO/CMC- $\mathrm{Cr}_{2} \mathrm{O}_{3}$ were casted in Petri dishes and left in an oven for about three days at $50{ }^{\circ} \mathrm{C}$ to evaporate the solvent. The thickness of the samples is measured at about $120 \mu \mathrm{m}$. The obtained the PEO/CMC- $\mathrm{Cr}_{2} \mathrm{O}_{3}$ nanocomposite films were stored until characterized.

\subsection{Measurements}

The PEO/CMC- $\mathrm{Cr}_{2} \mathrm{O}_{3}$ nanocomposite samples were studied using the X-ray diffractometer with $\mathrm{CuK} \alpha$ target and the wavelength $1.5408 \AA$ (Model D/Max2500VB2+/PC, Rigaku Co., Japan) with Bragg's angle $2 \theta$ $=5-70^{\circ}$. Fourier transform infrared (FT-IR) absorption spectra were obtained in wavenumber $4000-400 \mathrm{~cm}^{-1}$ using FT-IR spectrometer (Model Nicolet iS10 spectrometer, USA). The ultra and visible (UV-vis) 
measurements were obtained by Jasco 570 spectrometer in the range of wavelength about 190-1000 $\mathrm{nm}$. The electrical conductivity data were recorded using Novocontrol turnkey concept 40 System at a frequency of about $0.1 \mathrm{~Hz}-7 \mathrm{MHz}$.

\section{Results and discussion}

\subsection{X-ray diffraction}

The X-ray diffraction of pure $\mathrm{Cr}_{2} \mathrm{O}_{3}$ nanoparticles is shown as insert in Fig. 1. The X-ray peaks of pure $\mathrm{Cr}_{2} \mathrm{O}_{3}$ nanoparticles found in the figure are agreement with the literature $[12,14]$. The $X$-ray peaks at $2 \theta=$ $24.8,32.6,33.2,41.4,50,6,85,5,63.4$ and $65.3^{\circ}$ which are assigned to Bragg reflections (012), (104), (110), (113), (024), (116), (214) and (300), respectively. The crystalline peaks are defined cubic and orthorhombic shape and indexed according to JCPDS 84-1616.

The X-ray diffraction of pure $\mathrm{PEO} / \mathrm{CMC}$ polymer blend and the blend filled with $0.0,0.2,0.4$ and 0.6 wt. $\%$ of $\mathrm{Cr}_{2} \mathrm{O}_{3}$ nanoparticles at the Bragg's angle $2 \theta$ from about $5-70^{\circ}$ at room temperature is recorded in Fig. 1. From literature, the pure PEO has two broad peaks at $2 \theta \sim 19.7$ and $23.8^{\circ}$ and pure $\mathrm{CMC}$ is a non-crystalline structure with a broad peak at about $2 \theta \sim 20.4^{\circ}$ suggested to the amorphous nature structure for CMC pure polymer $[11,16,17]$.

The broad peak or the hump is observed in all samples. There is a decrease of the broad peak after the addition of $\mathrm{Cr}_{2} \mathrm{O}_{3}$ nanoparticles addition to other peaks at $2 \theta \sim 32.6,33.9,36.2$ and $40.8 .4^{\circ}$ which is attributed to $\mathrm{Cr}_{2} \mathrm{O}_{3}$ nanoparticles because of the interactions between the $\mathrm{OH}$ groups inside the polymeric matrices and $\mathrm{Cr}^{3+}$ ions. The decrease in the broad peak $2 \theta \sim 20.5^{\circ}$ with the disappear of some peaks causes an increase of the amorphous region (domain amorphous phase) in the 
$\mathrm{PEO} / \mathrm{CMC}-\mathrm{Cr}_{2} \mathrm{O}_{3}$ nanocomposite samples which increase the segmental motion inside the polymeric matrices and confirming the increase of the ionic mobility and increase of the ionic conductivity of the prepared nanocomposites.

The crystallite sizes (D) can be calculated from Scherer's formula as[18,19]:

$$
D=\frac{K \lambda}{\beta \cos \theta}
$$

where, $\mathrm{K} \sim 9, \lambda=\lambda=0.15406 \mathrm{~nm}$, and $\beta$ is the half width for the peak and half. The crystallite sizes are found to be in the range of 50-60 nm.

\subsection{FT-IR study}

The infrared spectroscopy (FT-IR) study is used to investigate and characterize the interaction between the components in the prepared nanocomposite samples. The FT-IR absorption spectra for the pure $\mathrm{PEO} / \mathrm{CMC}$ polymer blend the blend doped with different concentrations of $\mathrm{Cr}_{2} \mathrm{O}_{3}$ nanoparticles is shown in Fig. 2. The position and assignments of the main peaks of PEO and CMC polymers are to relate to as in the literature.

The FT-IR spectra display the main groups of both pure polymers PEO and $\mathrm{CMC}$ like $\mathrm{OH}, \mathrm{CH}_{2}, \mathrm{COO}^{-}$groups in the $\mathrm{CMC}$ and $\mathrm{C}-\mathrm{O}-\mathrm{C}$ function group in the PEO polymer. The chemical interactions that occur between PEO and CMC are attributed to the formation of the hydrogen bond between the $\mathrm{OH}$ groups in CMC and C-O-C of PEO. occur. The absorbance bands at wavelengths about $1591 \mathrm{~cm}^{-1}, 1416 \mathrm{~cm}^{-1}$ and 1347 $\mathrm{cm}^{-1}$ are observed. The intensity of the FT-IR bands at $2871 \mathrm{~cm}^{-1}, 1469$ $\mathrm{cm}^{-1}, 1347 \mathrm{~cm}^{-1}$ and $1281 \mathrm{~cm}^{-1}$ are nearly decreased confirming that to completely miscible and compatible between the two polymers [9,20-23]. 
The broad absorption band in the wavelength centered at about 3440 $\mathrm{cm}^{-1}$ is assigned to the symmetric and asymmetric stretching of $-\mathrm{NH}_{2}$, and $\mathrm{OH}$ groups. The band at $2871 \mathrm{~cm}^{-1}$ is assigned to the $\mathrm{C}-\mathrm{H}-\mathrm{CH}_{2}$ group in the pure CMC. The absorption band at $1590 \mathrm{~cm}$ is assigned to the asymmetric expansion of a -COO-. After the addition of $\mathrm{Cr}_{2} \mathrm{O}_{3}$ nanoparticles to the polymer blend, the intensity of the FT-IR bands at $2871 \mathrm{~cm}^{-1}, 1469 \mathrm{~cm}^{-1}, 1347 \mathrm{~cm}^{-1}$ and $1281 \mathrm{~cm}^{-1}$ are nearly decreased confirming that to completely miscible and compatible between the two polymers and $\mathrm{Cr}_{2} \mathrm{O}_{3}$ nanoparticles. This indicate that hydrogen gives new bonds in the catenary of the nanoparticles that these groups interact with the Cr nanoparticles as shown in Scheme 1.

\section{UV-Vis study}

The ultraviolet and visible (UV-Vis) absorption spectra of pure $\mathrm{PEO} / \mathrm{CMC}$ polymer blend and the blend doped with different concentrations of $\mathrm{Cr}_{2} \mathrm{O}_{3}$ are shown in Fig. 3. It is observed that the UVVis absorbance increased with increases of $\mathrm{Cr}_{2} \mathrm{O}_{3}$ nanoparticles inside the $\mathrm{PEO} / \mathrm{CMC}$ polymeric matrices. Two absorption bands found at 251 and $373 \mathrm{~nm}$ in all spectra of the prepared nanocomposites are $\mathrm{Cr}_{2} \mathrm{O}_{3}$ due to the formation of charge-transfer complexes.

The optical energy gap $\left(E_{g}\right)$ is estimated using UV-Vis spectra related to the frequency dependence of the energy. Detailed information about the band structure of nanocomposites can be obtained by studying optical absorption by exciting of the electrons from a lower energy level to a higher energy level than by absorbing the amount of energy (photon) enough to transition. The optical absorption coefficient $(\alpha)$ (The ability of the sample to absorb light related to the wavelength) is given from the Beer-Lambert's relation as[24,25]: 


$$
\alpha=\frac{2.303 A}{d}
$$

where $\mathrm{A}$ is the absorbance and $\mathrm{A}$ is the thickness of the sample. optical absorption coefficient $(\alpha)$ can be estimated using the absorbance from the equation[26,27]:

$$
\alpha h v=B\left(h v-E_{g}\right)^{n}
$$

where $\mathrm{B}$ is a constant and $\mathrm{n}$ is equal 1/2,3/2, 2 or 3 for direct allowed direct forbidden, indirect allowed and indirect forbidden transition, respectively. The graph of $(\alpha h v)^{1 / 2}$ against the energy of the photon (hv) gives us to determine the values of the optical energy gap $\left(E_{g}\right)$ using extrapolating the linear part of $(\alpha h v)^{1 / 2}$ at zero as we see in Fig. 4. The value of $\mathrm{E}_{\mathrm{g}}$ of pure $\mathrm{PEO} / \mathrm{CMC}$ blend agreement with previous works. After the addition of $\mathrm{Cr}_{2} \mathrm{O}_{3}$ nanoparticles, the values $\mathrm{E}_{\mathrm{g}}$ are decreased due to the increased occurrence of the interaction between $\mathrm{Cr}_{2} \mathrm{O}_{3}$ and $\mathrm{OH}$ groups inside the $\mathrm{PEO} / \mathrm{CMC}$ polymer blend and due to incorporation of the $\mathrm{Cr}_{2} \mathrm{O}_{3}$ forms charge transfer complex inside PEO/CMC matrices. The presence of the charge-transfer causes an increase in the AC electrical conductivity $\left(\sigma_{\mathrm{ac}}\right)$. Finally, the decrease of the optical energy band gap is due to the impurity amount in the localized state through the band gap which finally decreases the $\mathrm{E}_{\mathrm{g}}$ values. These results are consistent with the results in the X-ray study and the AC electrical conductivity data.

\subsection{Electrical conductivity study}

\section{4.i. AC electrical conductivity}

The values of $\mathrm{AC}$ electrical conductivity $\left(\sigma_{\mathrm{ac}}\right)$ of $\mathrm{PEO} / \mathrm{CMC}-\mathrm{Cr}_{2} \mathrm{O}_{3}$ nanocomposite samples is estimated from the equation:

$$
\sigma_{a c}=\frac{t \cdot C}{A}
$$

where, $\mathrm{t}$ is thickness, $\mathrm{A}$ the cross-sectional area and $\mathrm{C}$ is the conductance of the used nanocomposite samples. Fig. 5 shows the relation between 
the $\log \left(\sigma_{\mathrm{ac}}\right)$ versus frequency of $\mathrm{PEO} / \mathrm{CMC}-\mathrm{Cr}_{2} \mathrm{O}_{3}$ nanocomposite samples at room temperature in the range of the frequency from $1 \mathrm{~Hz}$ to 7 MHz. Generally, the gradual increases in the AC electrical conductivity with an increase of frequency is common behaviour for the polymer nanocomposites. There are three phases in the AC conductivity spectra as we see in the figure. The low frequency at the first region shows low values of the $\mathrm{AC}$ conductivity attributed to the electrode polarization related to the slow periodic reversal of the electric field. The plateau region is found at the medium range of frequency (DC conductivity could be evaluated in this region). The third region is clear at the high frequency due to space charge polarization at the blocking electrodes.

The AC conductivity values increase with an increase of the addition of $\mathrm{Cr}_{2} \mathrm{O}_{3}$ confirms to the presence of charge carriers that could be carried via hopping in defect sites along polymer chains. The raise in $\sigma_{\mathrm{ac}}$ is discussed according to the extended chain length inside the $\mathrm{PEO} / \mathrm{CMC}$ matrices that allows the hopping of the charge carriers and this supports the carriers of charge to hop between the favourable localized sites. This can be due to the tendency in polymeric samples of the dipoles to orient themselves in the direction of the field applied. However, in the high frequency range, as opposed to the lower frequency region, the growing pattern seems to be sharp. On all graphs with various concentrations of metals, this effect is found.

\section{4. ii. The dielectric permittivity}

Figs. 6 and 7 show the complex dielectric permittivity, real part $\left(\varepsilon^{\prime}\right)$ and loss part $\left(\varepsilon^{\prime \prime}\right)$, spectra of PEO/CMC- $\mathrm{Cr}_{2} \mathrm{O}_{3}$ films. The values of the $\varepsilon^{\prime}$ are a clear indicator of its capacity to store electrical energy, while the values of $\varepsilon^{\prime \prime}$ the energy loss in the dielectric. The values of $\varepsilon^{\prime}$ are exponentially decreased as a raise of the frequency and it approaches the 
stable level above $300 \mathrm{kHz}$. The higher values for $\varepsilon^{\prime}$ are measured at lower frequencies due to the dominant contribution of the interfacial polarization affect which display an accumulation of charges with various conductivity within the dielectric materials, obtain from the micro capacitances over the whole volume of material.

In general, the nanocomposite samples in this article have a three phase (two for PEO/CMC blend and the other phase for $\mathrm{Cr}_{2} \mathrm{O}_{3}$ nanoparticles. Then, the values of $\varepsilon^{\prime}$ are high with an increase as increases of $\mathrm{Cr}_{2} \mathrm{O}_{3}$ which is attributed to the high value of dielectric permittivity of $\mathrm{Cr}_{2} \mathrm{O}_{3}$ nanoparticles. An increase of $\varepsilon^{\prime}$ is occurred due to the interactions between the $\mathrm{Cr}_{2} \mathrm{O}_{3}$ nanoparticles with the polar functional groups inside the $\mathrm{PEO} / \mathrm{CMC}$ polymer blend and the changing of the dipolar ordering gives the variation of the dielectric properties. As we see in figure 7 , the spectra $\varepsilon^{\prime \prime}$ exhibit dramatically increase up to $3 \mathrm{kHz}$ which is attributed to the interfacial polarization effect.

The high value of $\varepsilon^{\prime \prime}$ confirms the raise of the energy loss per cycle inside the nanocomposite films. After the addition of $\mathrm{Cr}_{2} \mathrm{O}_{3}$, the increase of $\varepsilon^{\prime \prime}$ values are related The effects of $\mathrm{AC}$ conduction loss are appear from space charges such as ions or electrons and due to the reorientation of the dipolar.

\section{4. ii. The complex dielectric modulus}

The complex dielectric modulus $\left(\mathrm{M}^{*}\right)$ is used to study the relaxation phenomena in $\mathrm{AC}$ electrical behaviour. The modulus $\left(\mathrm{M}^{*}\right)$ is calculated as:

$$
\begin{gathered}
\mathrm{M}^{*}=\frac{1}{\varepsilon^{*}}=\mathrm{M}^{\prime}+\mathrm{M}^{\prime \prime} \\
\mathrm{M}^{\prime}=\frac{\varepsilon^{\prime}}{\varepsilon^{\prime 2}+\varepsilon^{\prime \prime 2}} \quad \text { and } \quad \mathrm{M}^{\prime \prime}=\frac{\varepsilon^{\prime \prime}}{\varepsilon^{\prime 2}+\varepsilon^{\prime 2}}
\end{gathered}
$$


where $\mathrm{M}^{\prime}$ is the real part of the electric modulus and $\mathrm{M}^{\prime \prime}$ is the imaginary part of the electric modulus. Figs. 8 and 9 obtain the behaviour of both $\mathrm{M}^{\prime}$ and $\mathrm{M}^{\prime \prime}$ against the $\log$ of the frequency. From the figures, at low frequencies, the values of both $\mathrm{M}^{\prime}$ and $\mathrm{M}^{\prime \prime}$ attends almost zero, assigned to the negligible contribution of electrode polarization.

The low values of the two complex modules suggest that the electrode effect has a marginal electrode polarisation contribution and can thus be overlooked. The step-like transformation approaches an asymptotic value relative to the frequency and represents the extremely capacitive nature of the samples. At medium of frequency, the values of $\mathrm{M}^{\prime}$ is linear increase with increases of frequency and exponentially increase at high frequency.

In the M" graph, it found a relaxation peak that offers an indicator of the existence of the phase transition that occurs attributed to the transition regions from long-range ionic (translation) to short-range (dipolar) mobility. The magnitude of $\mathrm{M}^{\prime \prime}$ peak is increases with increases of the $\mathrm{Cr}_{2} \mathrm{O}_{3}$ nanoparticles. The shift for the position of the peak to low frequency occurs as an increase of $\mathrm{Cr}_{2} \mathrm{O}_{3}$ nanoparticles increases the conductivity relaxation time.

Fig. 10 shows the diagram between the real part $\left(\mathrm{M}^{\prime}\right)$ and the imaginary $\left(\mathrm{M}^{\prime \prime}\right)$. The diagram shows the half semicircle which discusses according to the Debye style relaxation mechanism and the absence of contact effects. This specific function is attributed to the grain site or due to the mobility of free charges caused by interactions between both the components of the blend. Then, relaxation is due to the complex of conductivity relaxation. With the rise in $\mathrm{Cr}_{2} \mathrm{O}_{3}$ nanoparticles, the collected semicircle increases, indicating that this sample is more conductive. 
Two relaxation regions were appeared below and above the $\mathrm{M}^{\prime \prime}$ peak. The DC conductivity arising from the continuous hopping phase in which the charge carriers are mobile over long distances can be connected to the area of low frequencies. Although the area of the highfrequency side is due to the mechanism of relaxation polarisation and indicates the spectrum of frequencies at which the ions were confined spatially to their potential wells and the ions can only pass inside the wells in the short range. The AC conductivity-related right side of the peak benefits from the reversible motion of ions over a small space. Therefore, the peak frequency reflects the change from long to short of the mobility as increase in frequencies.

\section{Conclusions}

The solution casting method was used to prepare polymer nanocomposite films based on $\mathrm{PEO} / \mathrm{CMC}$ blend incorporated with different contents of $\mathrm{Cr}_{2} \mathrm{O}_{3}$ nanoparticles. The main crystalline X-ray peaks of $\mathrm{Cr}_{2} \mathrm{O}_{3}$ were found with defined a cubic structure, orthorhombic shape and crystallite size $\sim 50-60 \mathrm{~nm}$. The broad peak (hump) in pure $\mathrm{PEO} / \mathrm{CMC}$ blend was decreased after the addition of $\mathrm{Cr}_{2} \mathrm{O}_{3}$ causing an increase in the amorphous region causes increase of the segmental motion and an increase of the ionic conductivity of the PEO/CMC- $\mathrm{Cr}_{2} \mathrm{O}_{3}$ nanocomposites. The intensity of FT-IR bands was decreased confirming miscible and compatible between $\mathrm{PEO} / \mathrm{CMC}$ and $\mathrm{Cr}_{2} \mathrm{O}_{3}$ nanoparticles. The optical absorbance was enhanced after the addition of $\mathrm{Cr}_{2} \mathrm{O}_{3}$ nanoparticles within PEO/CMC polymeric chains. The optical energy band gap $\left(\mathrm{E}_{\mathrm{g}}\right)$ was decreased with increases in $\mathrm{Cr}_{2} \mathrm{O}_{3}$ contents due to the formation of charge-transfer complexes. The values of $\mathrm{AC}$ electrical conductivity $\left(\sigma_{\mathrm{ac}}\right)$ were increased with increases in frequency. Three phases in the AC conductivity spectra were observed. The first found at 
low frequency attributed to the accumulation of ions, plateau at the medium range of the frequency which discus the DC conductivity and the third phase at high frequency attributed to the space charge polarization. The values of the real part $\left(\varepsilon^{\prime}\right)$ and loss part $\left(\varepsilon^{\prime \prime}\right)$ were exponentially decreased as an increase of the frequency and it approaches nearly zero. Low values of the complex modulus indicate that the electrode effect has a negligible contribution to electrode polarization. The plot between $\mathrm{M}^{\prime}$ and $\mathrm{M}^{\prime \prime}$ displays half semicircle which discusses according to the Debye type relaxation process.

\section{References}

[1] G. Patel, M.B. Sureshkumar, P. Patel, Spectroscopic Investigation and Characterizations of PAM/PEO Blends Films, Soft. 04 (2015) 9-24. doi:10.4236/soft.2015.42002.

[2] X. Wang, H. Lu, X. Liu, M. Hossain, Y.Q. Fu, B. Bin Xu, Dynamic coordination of miscible polymer blends towards highly designable shape memory effect, Polymer (Guildf). 208 (2020) 122946. doi:10.1016/j.polymer.2020.122946.

[3] S. Awad, S. El-Gamal, A.M. El Sayed, E.E. Abdel-Hady, Characterization, optical, and nanoscale free volume properties of Na-CMC/PAM/CNT nanocomposites, Polym. Adv. Technol. 31 (2020) 114-125. doi:10.1002/pat.4753.

[4] N. Yekeen, E. Padmanabhan, A.K. Idris, P.S. Chauhan, Nanoparticles applications for hydraulic fracturing of unconventional reservoirs: A comprehensive review of recent advances and prospects, J. Pet. Sci. Eng. 178 (2019) 41-73. doi:10.1016/j.petrol.2019.02.067.

[5] P.H.C. Camargo, K.G. Satyanarayana, F. Wypych, Nanocomposites: Synthesis, structure, properties and new 
application opportunities, Mater. Res. 12 (2009) 1-39. doi:10.1590/S1516-14392009000100002.

[6] I.S. Elashmawi, N.A. Hakeem, E.M. Abdelrazek, Spectroscopic and thermal studies of PS/PVAc blends, Phys. B Condens. Matter. 403 (2008) 3547-3552. doi:10.1016/j.physb.2008.05.024.

[7] T. Tanaka, G.C. Montanari, R. Mülhaupt, Polymer nanocomposites as dielectrics and electrical insulation- perspectives for processing technologies, material characterization and future applications, IEEE Trans. Dielectr. Electr. Insul. 11 (2004) 763-784. doi:10.1109/TDEI.2004.1349782.

[8] S. Choudhary, Structural and dielectric properties of (PEOPMMA)- $\mathrm{SnO}_{2}$ nanocomposites, Compos. Commun. 5 (2017) 5463. doi:10.1016/j.coco.2017.07.004.

[9] S.J. Doh, J.Y. Lee, D.Y. Lim, J.N. Im, Manufacturing and analyses of wet-laid nonwoven consisting of carboxymethyl cellulose fibers, Fibers Polym. 14 (2013) 2176-2184. doi:10.1007/s12221-0132176-y.

[10] A.H. Saputra, L. Qadhayna, A.B. Pitaloka, Synthesis and Characterization of Carboxymethyl Cellulose (CMC) from Water Hyacinth Using Ethanol-Isobutyl Alcohol Mixture as the Solvents, Int. J. Chem. Eng. Appl. 5 (2014) 36-40. doi:10.7763/ijcea.2014.v5.347.

[11] L.H. Gaabour, Effect of selenium oxide nanofiller on the structural, thermal and dielectric properties of CMC/PVP nanocomposites, J. Mater. Res. Technol. 9 (2020) 4319-4325. doi:10.1016/j.jmrt.2020.02.057.

[12] W.S. Zhang, E. Brück, Z.D. Zhang, O. Tegus, W.F. Li, P.Z. Si, D.Y. Geng, K.H.J. Buschow, Structure and magnetic properties of $\mathrm{Cr}$ nanoparticles and $\mathrm{Cr} 2 \mathrm{O} 3$ nanoparticles, Phys. B Condens. 
Matter. 358 (2005) 332-338. doi:10.1016/j.physb.2005.01.469.

[13] A. Hassen, A.M. El Sayed, W.M. Morsi, S. El-Sayed, Influence of $\mathrm{Cr} 2 \mathrm{O} 3$ nanoparticles on the physical properties of polyvinyl alcohol, J. Appl. Phys. 112 (2012). doi:10.1063/1.4764864.

[14] D.K. Singh, R.R. Yadav, D.K. Pandey, Synthesis and nondestructive characterization of $\mathrm{Cr} 2 \mathrm{O} 3$ nanoparticles-PVA suspensions, Adv. Mater. Res. 67 (2009) 259-264. doi:10.4028/www.scientific.net/AMR.67.259.

[15] S.A. Nouh, M.H. Abdel-Kader, M.B. Mohamed, Structural and Optical Modifications in Polyvinyl Alcohol Due to $\mathrm{Cr} 2 \mathrm{O} 3$ Nanoparticles Additives Concentration, and Gamma Irradiation, Adv. Polym. Technol. 36 (2017) 336-340. doi:10.1002/adv.21614.

[16] A. Abdel-Galil, H.E. Ali, A. Atta, M.R. Balboul, Influence of nanostructured $\mathrm{TiO} 2$ additives on some physical characteristics of carboxymethyl cellulose (CMC) , J. Radiat. Res. Appl. Sci. 7 (2014) 36-43. doi:10.1016/j.jrras.2013.11.004.

[17] I.S. Elashmawi, E.M. Abdelrazek, A.M. Hezma, A. Rajeh, Modification and development of electrical and magnetic properties of PVA/PEO incorporated with $\mathrm{MnCl} 2$, Phys. B Condens. Matter. 434 (2014) 57-63. doi:10.1016/j.physb.2013.10.038.

[18] S. Chandra, A. Kumar, Spectral, thermal and morphological studies of chromium nanoparticles, Spectrochim. Acta - Part A Mol. Biomol. $\quad$ Spectrosc. $102 \quad$ (2013) 250-255. doi:10.1016/j.saa.2012.10.003.

[19] N. Rani, S. Chahal, A.S. Chauhan, P. Kumar, R. Shukla, S.K. Singh, X-ray Analysis of $\mathrm{MgO}$ Nanoparticles by Modified Scherer's Williamson-Hall and Size-Strain Method, Mater. Today Proc. 12 (2019) 543-548. doi:10.1016/j.matpr.2019.03.096.

[20] P. Basu, A. Repanas, A. Chatterjee, B. Glasmacher, U. 
NarendraKumar, I. Manjubala, PEO-CMC blend nanofibers fabrication by electrospinning for soft tissue engineering applications, Mater. Lett. 195 (2017) 10-13. doi:10.1016/j.matlet.2017.02.065.

[21] G. Patel, M.B. Sureshkumar, P. Patel, Spectroscopic Investigation and Characterizations of PAM/PEO Blends Films, Soft. 04 (2015) 9-24. doi:10.4236/soft.2015.42002.

[22] A.R. Polu, H.W. Rhee, The effects of LiTDI salt and POSS-PEG (n $=4$ ) hybrid nanoparticles on crystallinity and ionic conductivity of PEO based solid polymer electrolytes, Sci. Adv. Mater. 8 (2016) 931-940. doi:10.1166/sam.2016.2657.

[23] A. Rajeh, M.A. Morsi, I.S. Elashmawi, Enhancement of spectroscopic, thermal, electrical and morphological properties of polyethylene oxide/carboxymethyl cellulose blends: Combined FTIR/DFT, $\quad$ Vacuum. $159 \quad$ (2019) 430-440. doi:10.1016/j.vacuum.2018.10.066.

[24] T. Siddaiah, P. Ojha, N.O.G.V.R. Kumar, C. Ramu, Structural, Optical and Thermal Characterizations of PVA/MAA:EA Polyblend Films, Mater. Res. 21 (2018). doi:10.1590/1980-5373mr-2017-0987.

[25] A.M. Gaur, D.S. Rana, Structural, optical and electrical properties of $\mathrm{MgCl} 2$ doped polyvinylidene fluoride (PVDF) composites, $\mathrm{J}$. Mater. Sci. Mater. Electron. 26 (2014) 1246-1251. doi:10.1007/s10854-014-2533-7.

[26] G. Sharma, M. Naushad, D. Pathania, A. Kumar, A multifunctional nanocomposite pectin thorium(IV) tungstomolybdate for heavy metal separation and photoremediation of malachite green, Desalin. Water $\quad$ Treat. $57 \quad$ (2016) 19443-19455. doi:10.1080/19443994.2015.1096834. 
[27] M.I. Mohammed, Optical properties of $\mathrm{ZnO}$ nanoparticles dispersed in PMMA/PVDF blend, J. Mol. Struct. 1169 (2018) 9-17. doi:10.1016/j.molstruc.2018.05.024. 
Table 1: The wavenumber with the assignments of the main characteristic FT-IR bands of PEO and CMC polymers.

\begin{tabular}{|c|c|c|c|}
\hline \multicolumn{2}{|c|}{ FT-IR assignment of pure PEO } & \multicolumn{2}{|c|}{ FT-IR assignment of CMC } \\
\hline $\begin{array}{c}\text { wavenumber } \\
\qquad\left(\mathrm{cm}^{-1}\right)\end{array}$ & assignment & $\begin{array}{c}\text { wavenumber } \\
\qquad\left(\mathrm{cm}^{-1}\right)\end{array}$ & assignment \\
\hline 842 & $\mathrm{CH}_{2}$ rocking mode & 1051 & $\begin{array}{l}\mathrm{CH}-\mathrm{O}-\mathrm{CH}_{2} \\
\text { stretching mode }\end{array}$ \\
\hline 954 & $\mathrm{C}-\mathrm{O}$ stretching mode & 1347 & OH bending mode \\
\hline 1104 & C-O-C stretching & 1414 & $\mathrm{CH}_{2}$ scissoring mode \\
\hline 1244 & $\begin{array}{l}\mathrm{CH}_{2} \text { symmetric twisting } \\
\text { mode }\end{array}$ & 1590 & $\begin{array}{l}\mathrm{COO}^{-} \quad \text { stretching } \\
\text { mode }\end{array}$ \\
\hline 1282 & $\begin{array}{l}\mathrm{CH}_{2} \quad \text { asymmetric } \\
\text { twisting mode }\end{array}$ & 2871 & $\begin{array}{l}\mathrm{CH}_{2} \text { asymmetric } \\
\text { stretching mode }\end{array}$ \\
\hline 1469 & $\mathrm{C}-\mathrm{H}$ bending mode & 3440 & OH stretching mode \\
\hline 2871 & $\begin{array}{l}\mathrm{CH}_{2} \quad \text { asymmetric } \\
\text { stretching mode }\end{array}$ & & \\
\hline
\end{tabular}


Figures

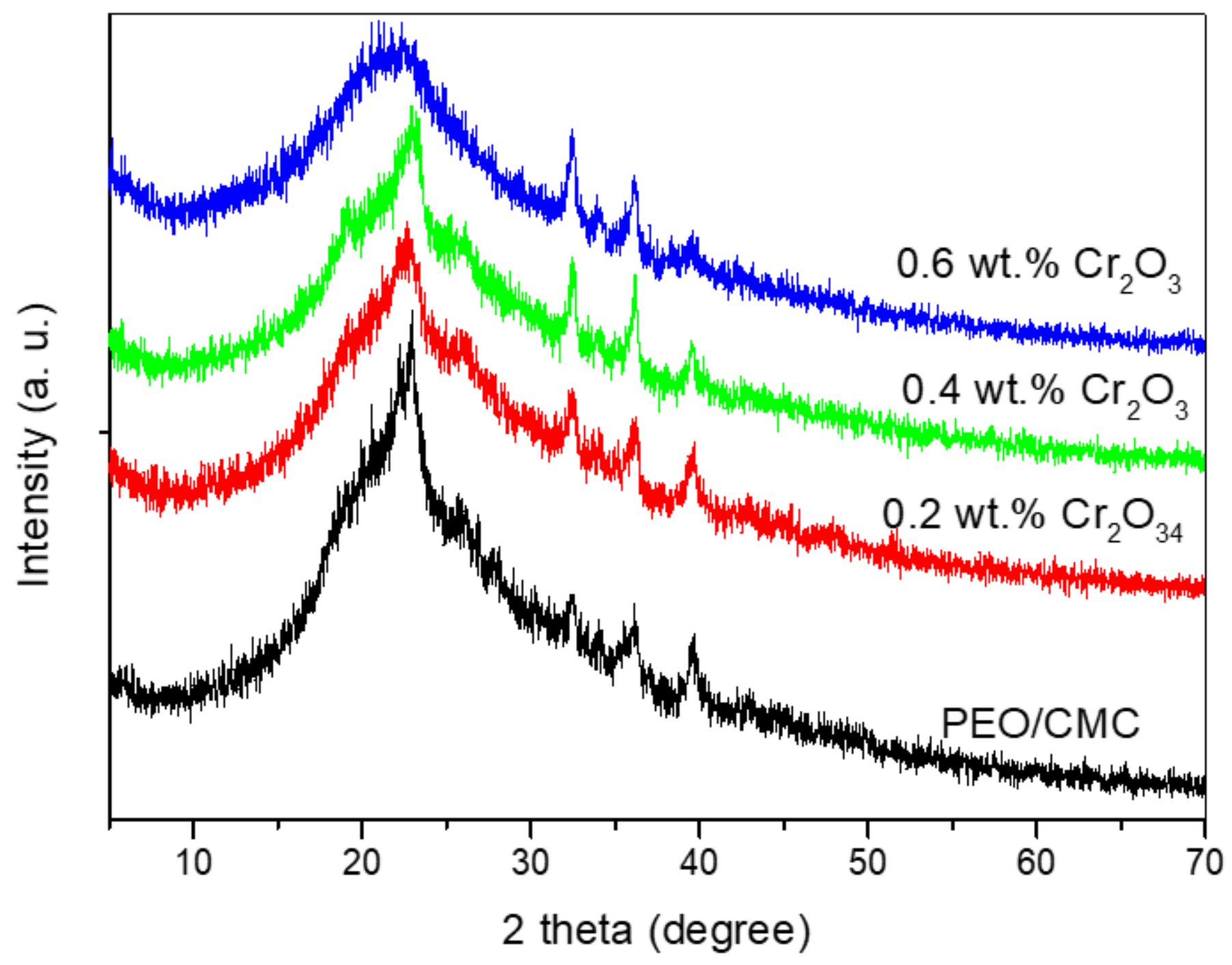

Figure 1

X-ray diffraction of PEO/CMC blend incorporated with $(0.0,0.2,0.4$ and $0.6 \%)$ of $\mathrm{Cr} 2 \mathrm{O} 3$ nanoparticles. 


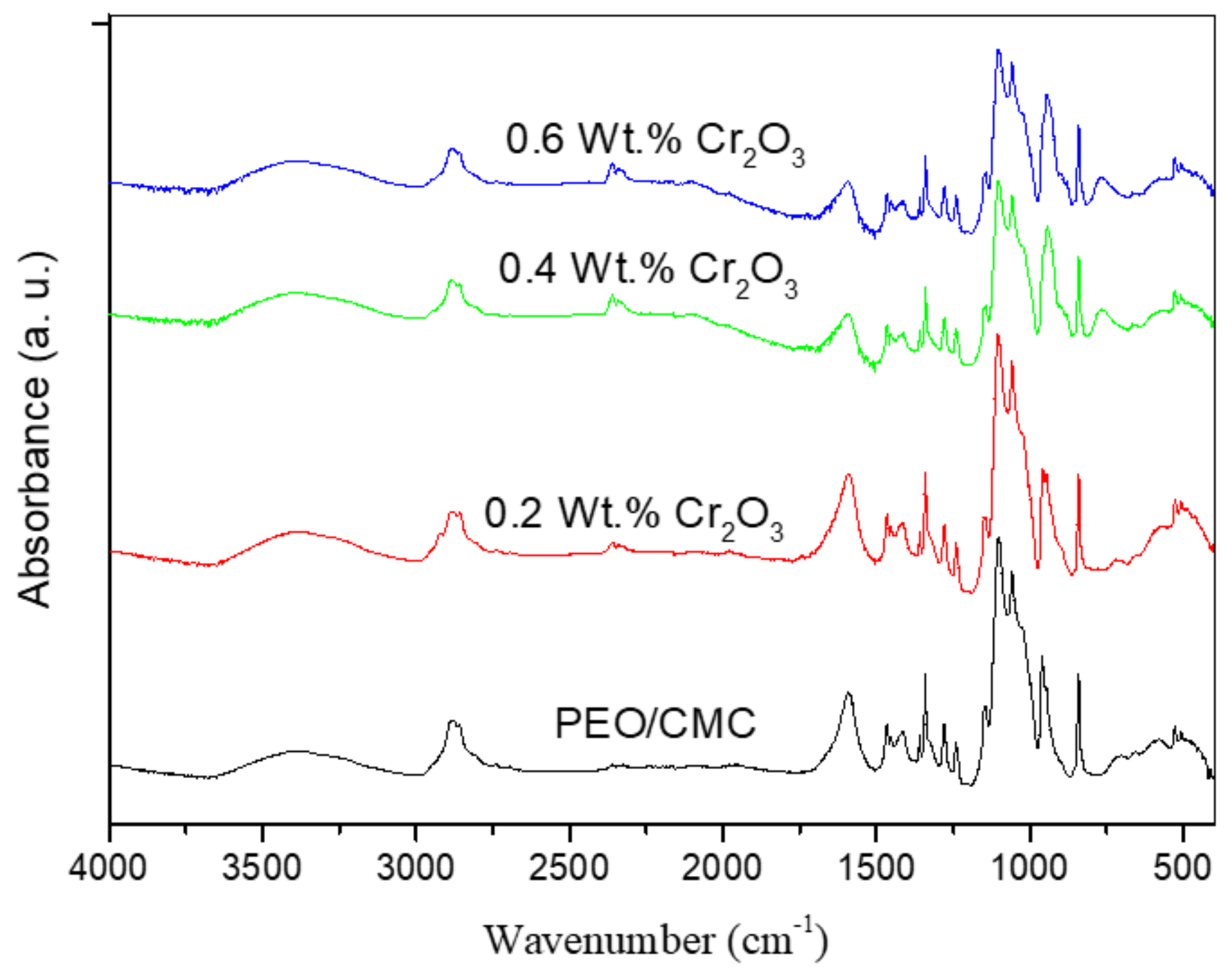

Figure 2

The FT-IR absorption spectra for PEO/CMC blend incorporated with $(0.0,0.2,0.4$ and $0.6 \%)$ of $\mathrm{Cr} 203$ nanoparticles. 


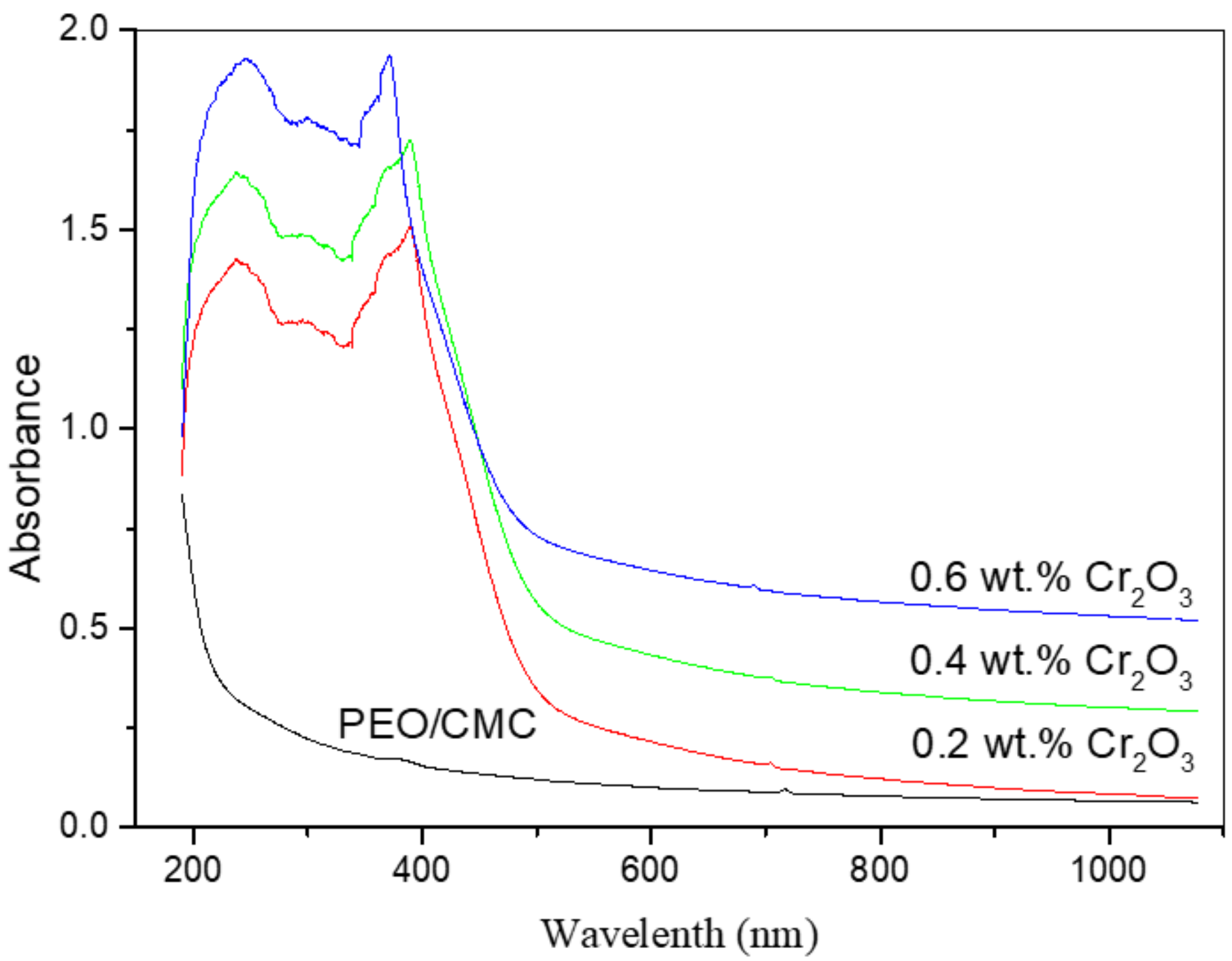

Figure 3

The UV-Vis absorption of PEO/CMC incorporated with different concentrations of $\mathrm{Cr} 2 \mathrm{O} 3$ nanoparticles. 


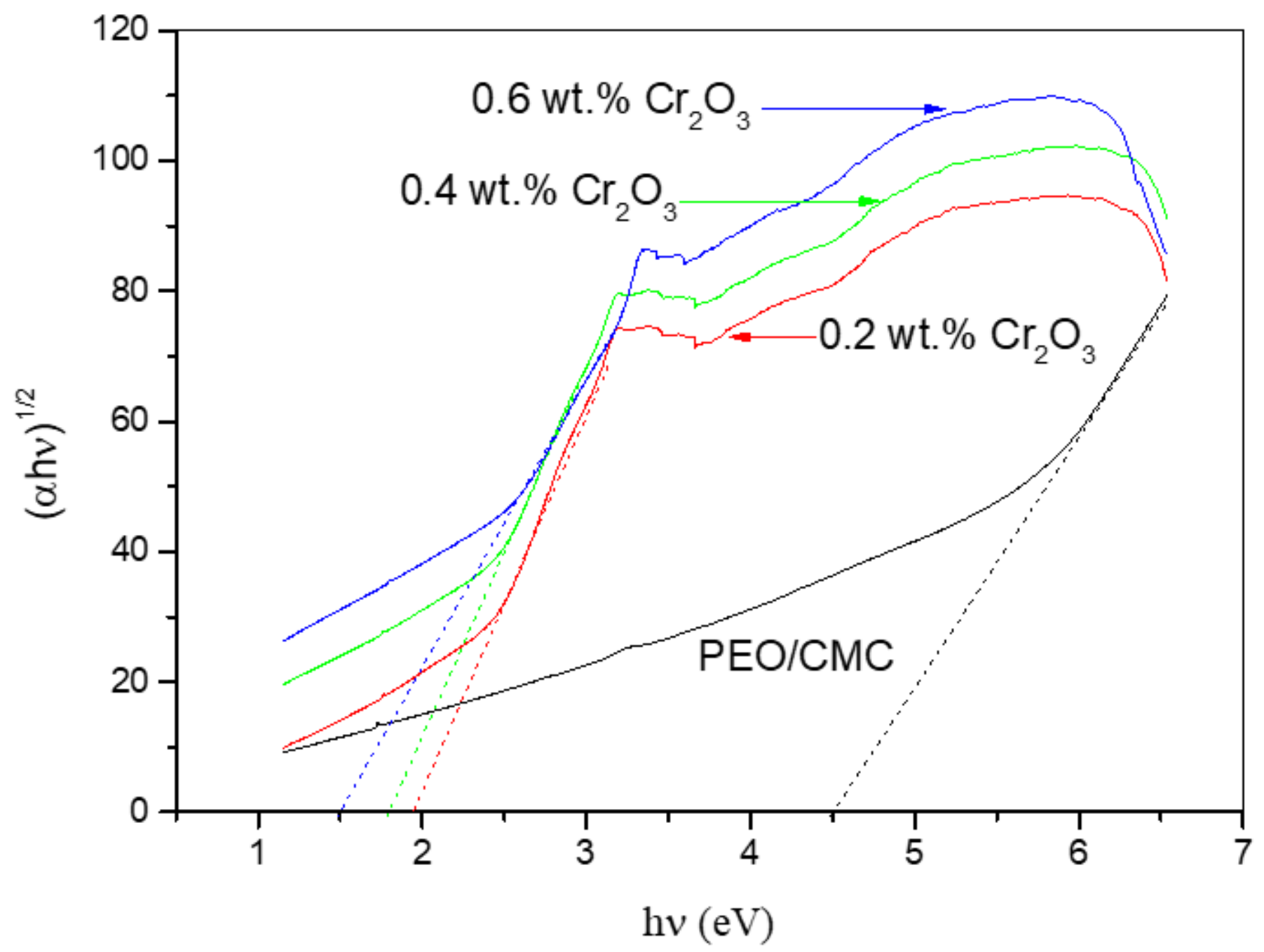

Figure 4

The relation between (ahu)1/2 and (hu) of PEO/CMC incorporated with different concentrations of $\mathrm{Cr} 2 \mathrm{O} 3$ nanoparticles. 


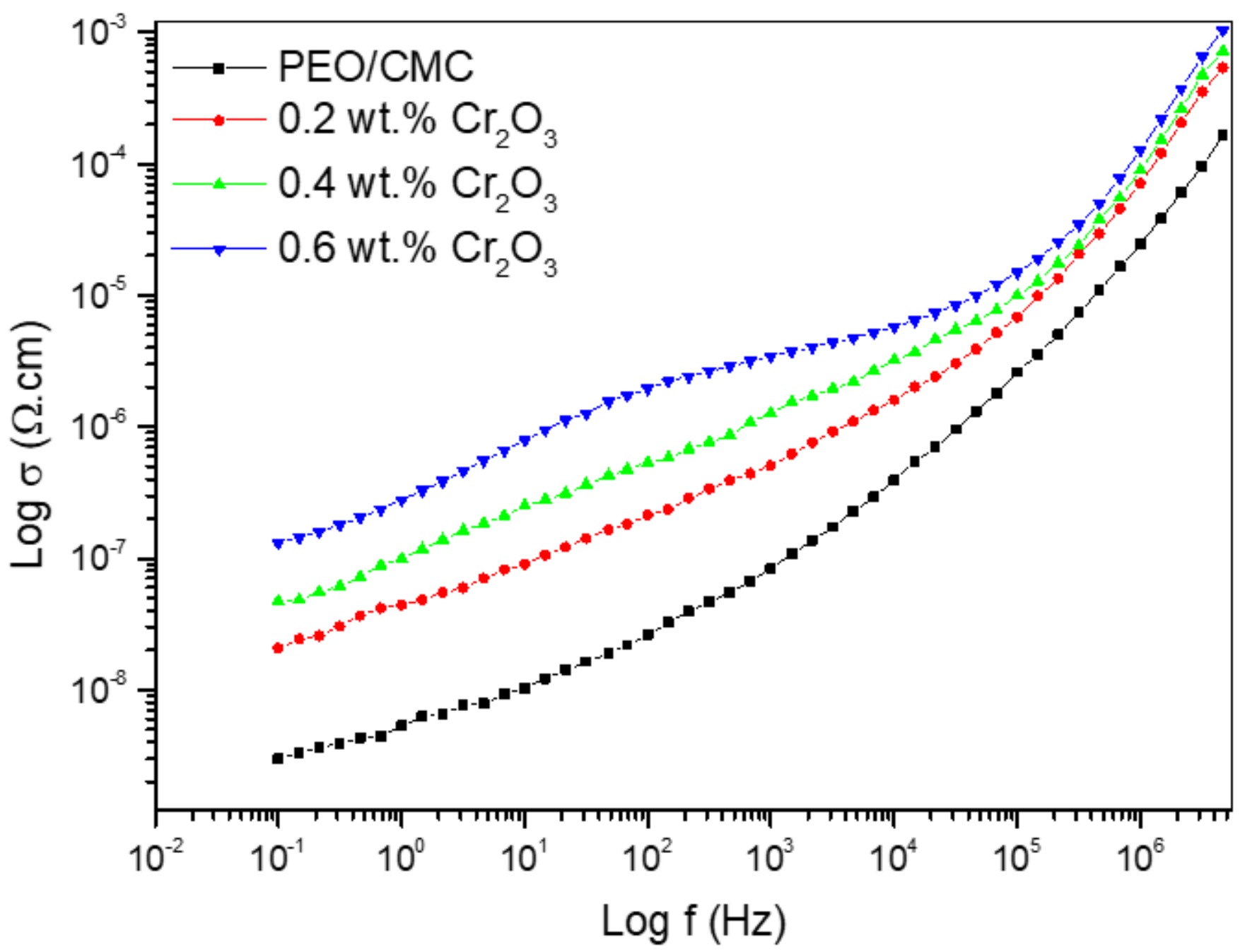

Figure 5

The variation the $A C$ electrical conductivity $(\log \sigma)$ ) against the frequency $(\log f)$ of PEO/CMC incorporated by concentrations of $\mathrm{Cr} 2 \mathrm{O} 3$ nanoparticles. 


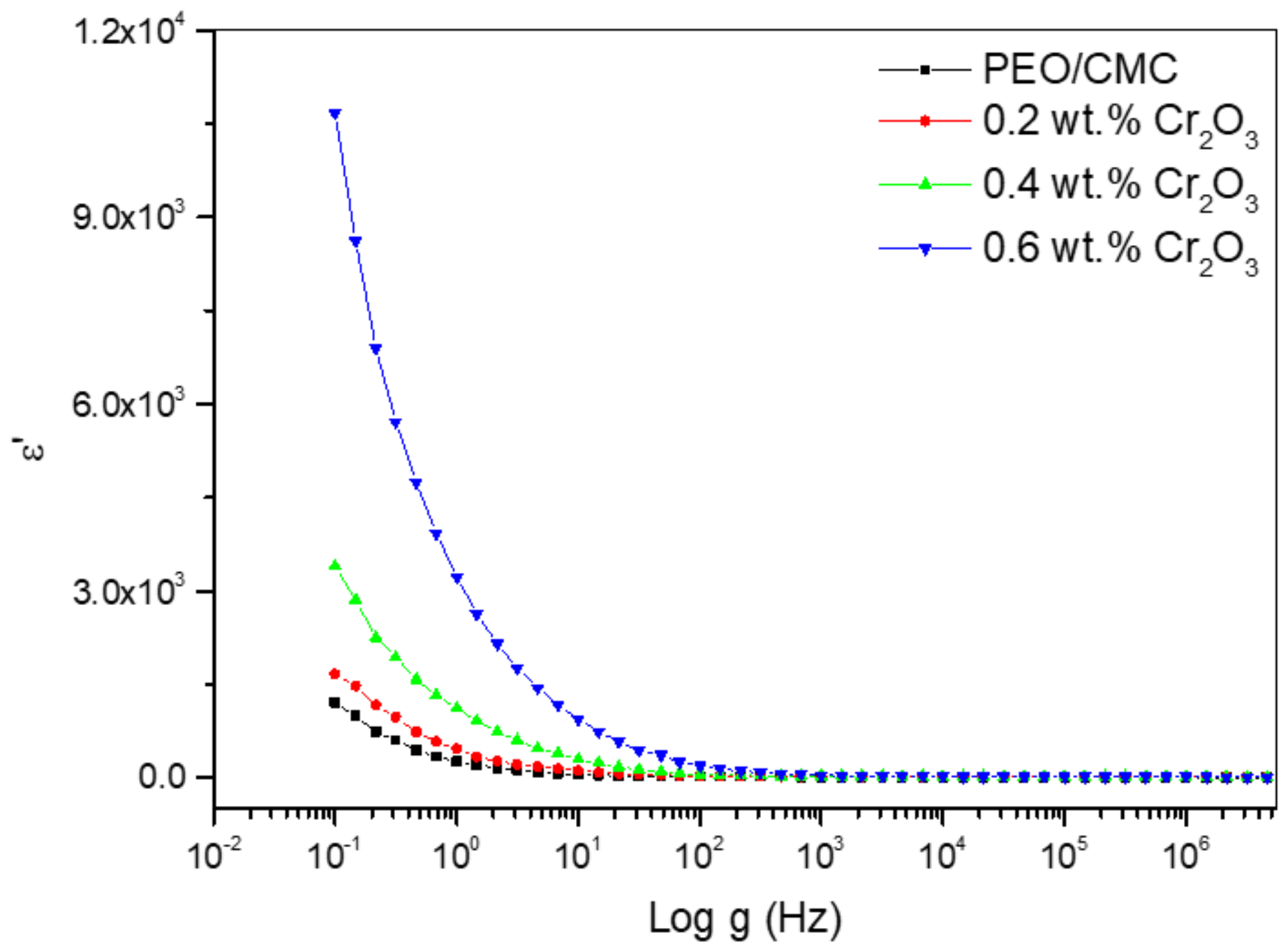

Figure 6

The plot between the dielectric constant $\left(\varepsilon^{\prime}\right)$ against the frequency ( $\left.\log f\right)$ of PEO/CMC incorporated different contents of $\mathrm{Cr} 2 \mathrm{O} 3$. 


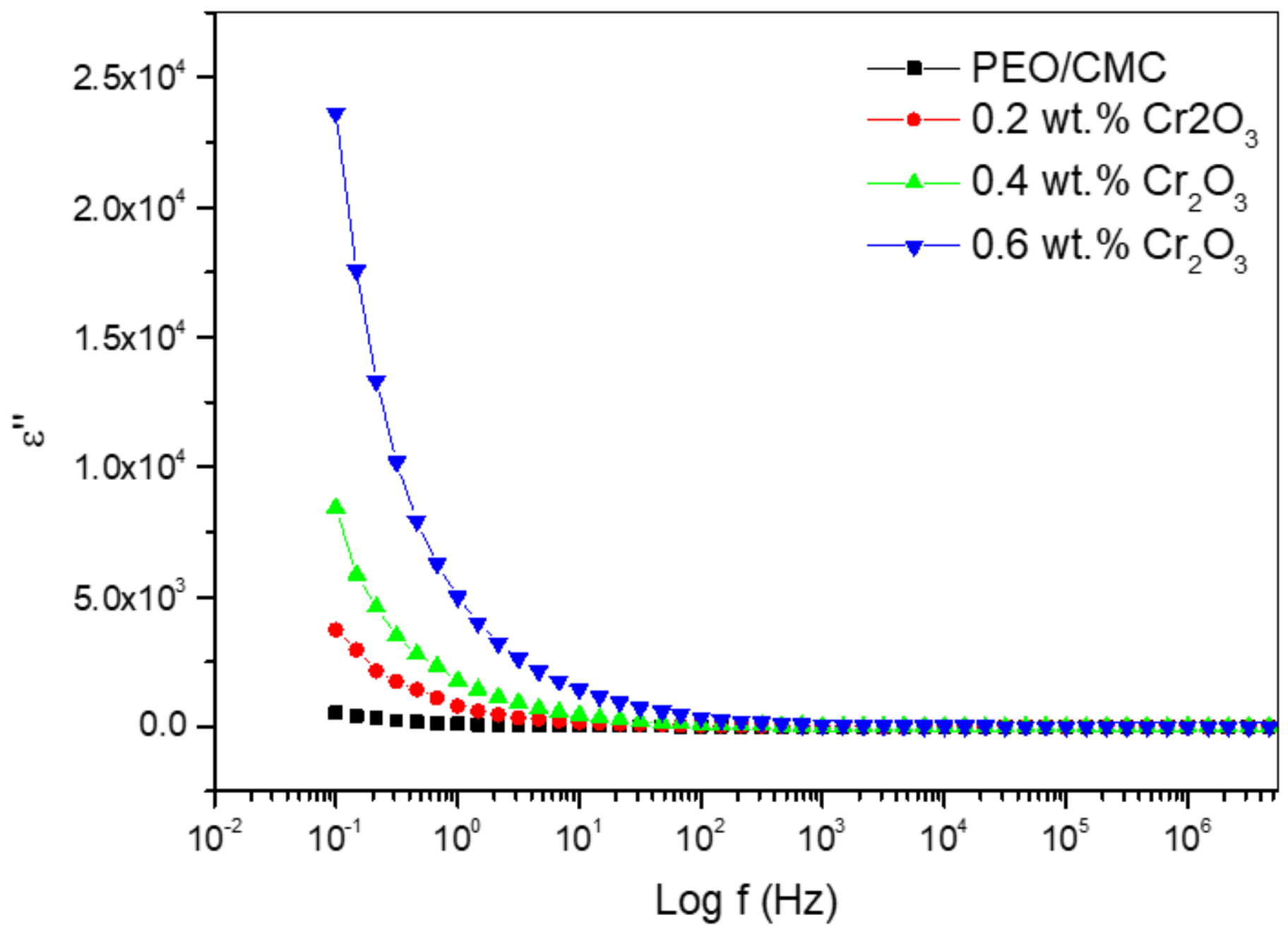

Figure 7

The relation between the dielectric loss $(\varepsilon ")$ against the frequency $(\log f)$ of PEO/CMC blend incorporated with different concentrations of $\mathrm{Cr} 2 \mathrm{O} 3$ nanoparticles. 


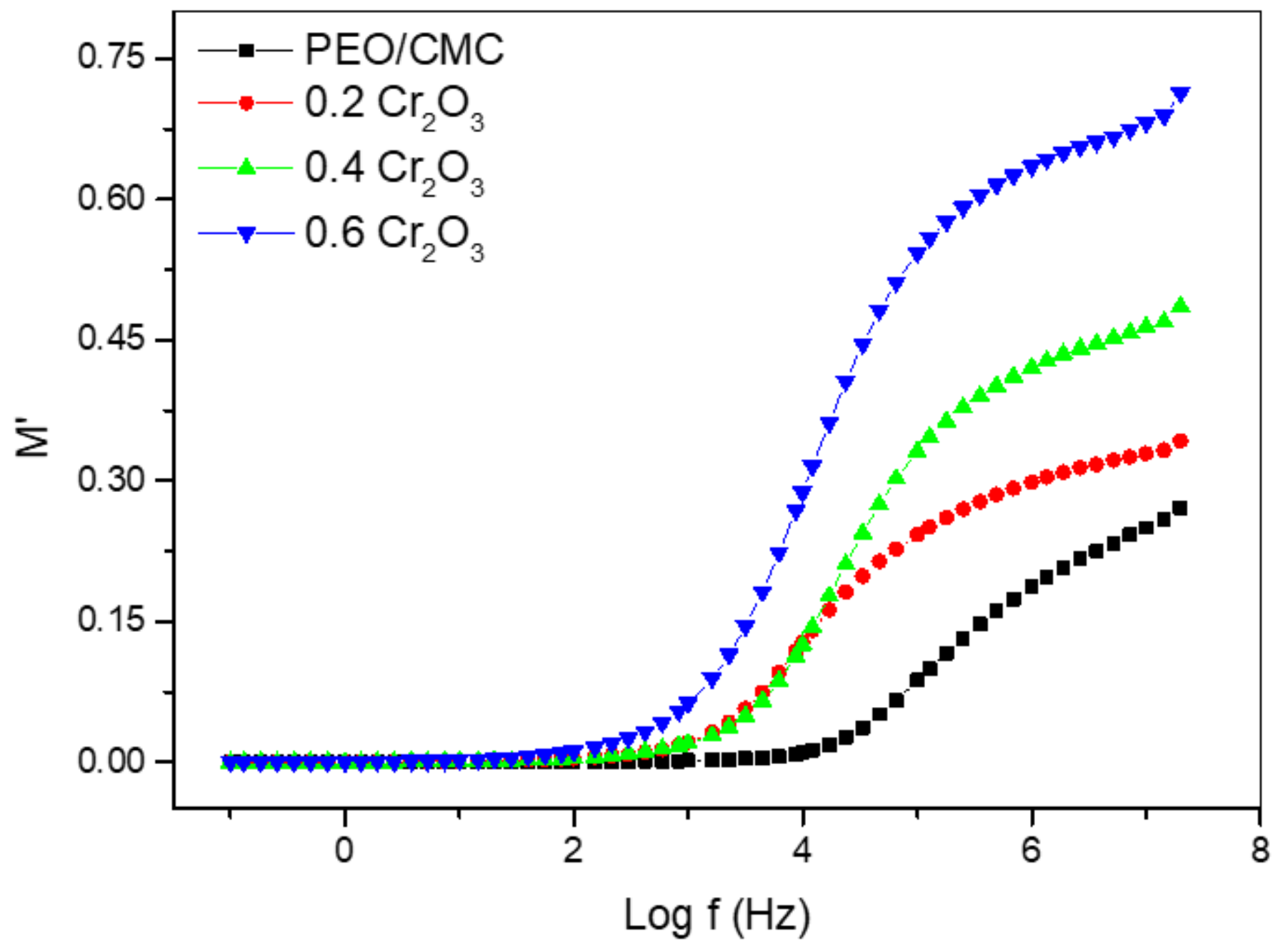

Figure 8

The relation between $M$ ' against the frequency $(\log f)$ of PEO/CMC incorporated by concentrations of Cr203 nanoparticles. 


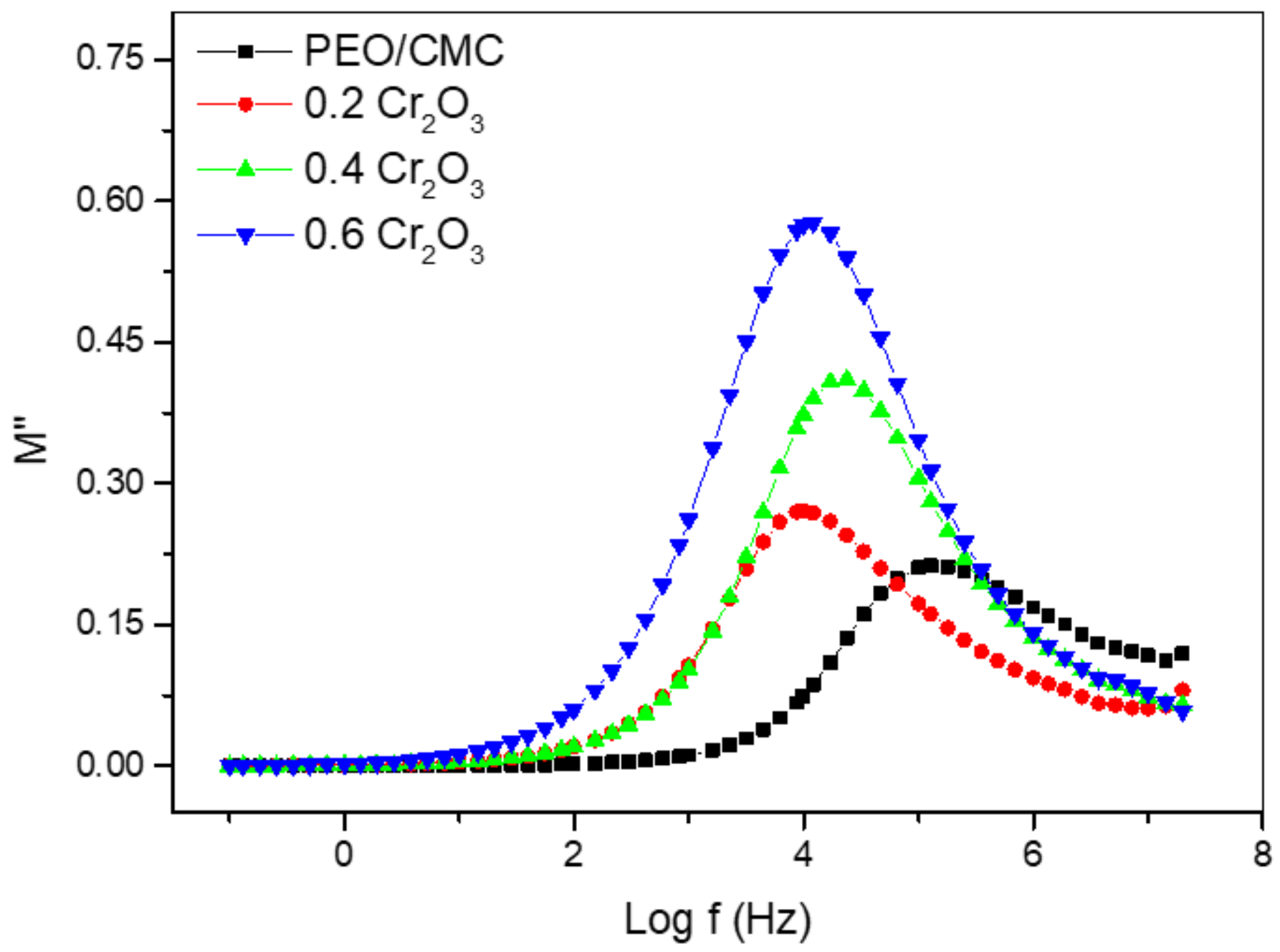

Figure 9

The relation between $\mathrm{M}$ " against the frequency $(\log \mathrm{f})$ of $\mathrm{PEO} / \mathrm{CMC}$ incorporated by concentrations of Cr2O3. 


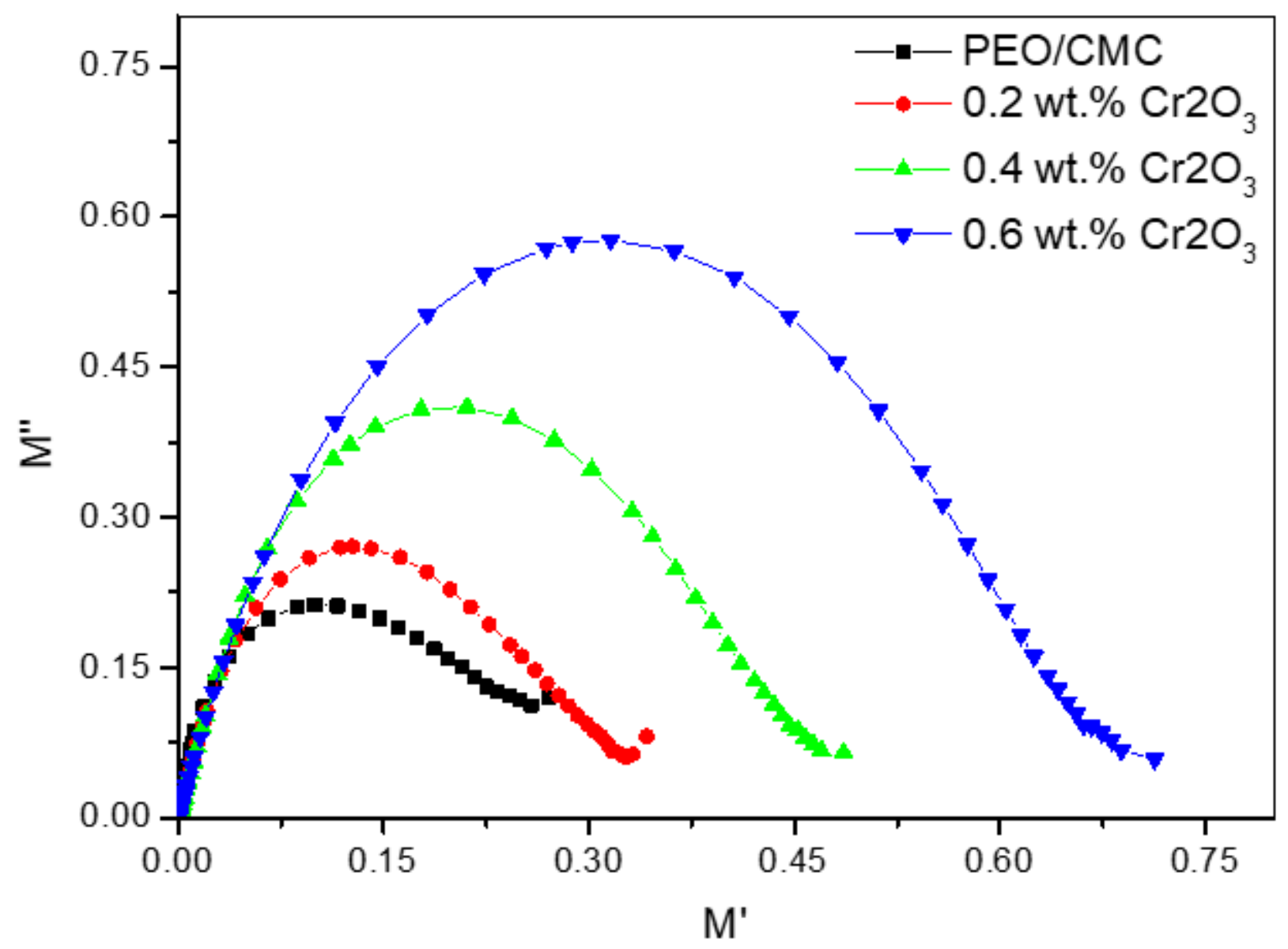

Figure 10

The Cole-Cole diagram between $\mathrm{M}^{\prime}$ and $\mathrm{M}^{\prime \prime}$ of PEO/CMC using different contents of Cr2O3.

\section{Supplementary Files}

This is a list of supplementary files associated with this preprint. Click to download.

- scheme1.png 